\title{
INVERSI 2D DATA MAGNETOTELURIK UNTUK MENGETAHUI KEBERADAAN HIDROKARBON DAERAH BULA, MALUKU
}

\author{
Elen Novia Limswipin*¹, Syamsurijal Rasimeng ${ }^{1}$, Karyanto ${ }^{1}$, Noor Muhammad \\ Indragiri $^{2}$ \\ ${ }^{1}$ Teknik Geofisika, Universitas Lampung \\ Jl. Prof. Dr. SumantriBrojonegoro No.1 BandarLampung 35145 \\ ${ }^{2}$ Pusat Survei Geologi \\ Jurusan Teknik Geofisika, FT UNILA \\ e-mail:*1elennovialimswipin@gmail.com
}

\begin{abstract}
ABSTRAK
Telah dilakukan penelitian dengan tema "inversi 2 dimensi data magnetotelurik untuk mengetahui keberadaan hidrokarbon daerah Bula, Maluku". Penelitian ini bertujuan untuk mengetahui distribusi resistivitas daerah penelitian berdasarkan data magnetotelurik, mengidentifikasi keberadaan hidrokarbon berdasarkan nilai resistivitas dari hasil inversi 2D data magnetotelurik. Metode pengolahan data yang dilakukan adalah (i) mengubah raw data dari domain waktu kedalam domain frekuensi, (ii) mereduksi noise dengan melakukan robust processing, (iii) melakukan proses combine, (iv) seleksi cross power, (v) melakukan inversi 1D dan 2D. Hasil inversi 2D yaitu penampang distribusi resistivitas bawah permukaan, lapisan yang memiliki nilai resistivitas 7 - $16 \Omega \mathrm{m}$ disepanjang titik MT1 dan MT7 pada kedalaman mencapai 1000 meter merupakan batu lempung yang diindikasikan sebagai cap rock. Lapisan dengan nilai resistivitas $34-120 \Omega \mathrm{m}$ yang berada diantara titik MT6 dan MT7 pada kedalaman 1500 meter merupakan batu pasir yang diindikasikan sebagai reservoar. Berdasarkan informasi geologi dan penampang inversi 2D terlihat adanya sesar berdasarkan nilai resistivitas yang kontras yaitu diantara titik MT2 dan MT3, MT3 dan MT4 serta MT6 dan MT7.
\end{abstract}

\begin{abstract}
There had been done a regional research which tittle is " $2 \mathrm{D}$ inversion magnetotelluric data for understanding the hidrocarbon presence in Bula, Maluku". This study aims to determine the resistivity distribution area of research based on data Magnetotelluric, identifying the presence of hydrocarbons based on the value of the resistivity of the results of 2D inversion of data Magnetotelluric. Methods of data processing done are (i) transform raw data from the time domain into the frequency domain, (ii) reduce noise by robust processing, (iii) process combine, (iv) Selection cross power, (v) inversion 1D and 2D. 2D inversion results is sectional subsurface resistivity distribution, layer having resistivity values 7-16 $\Omega \mathrm{m}$ along MT1 and MT7 point at a depth of 1000 meters is a clay stone which is indicated as cap rock. Layer with resistivity values 34-120 $\Omega \mathrm{m}$, which is between the point MT6 and MT7 at a depth of 1500 meters is indicated as the sandstone reservoir. Based on geologic information and sectional 2D inversion seen their fault based on the resistivity contrast is between the point MT2 and MT3, MT3 and MT4 and MT6 and MT7.
\end{abstract}

Keywords - magnetotelluric, $1 D$ inversion, 2D inversion, hidrocarbon, Bula 


\section{PENDAHULUAN}

Keterdapatan hidrokarbon di daerah Bula sudah diketahui sejak zaman perang dunia kedua (Gafoer dkk, 1993). Telah dilakukan penelitian sebelumnya oleh Styanta dan Setiadi pada tahun 2010 untuk mengetahui pola struktur dan geodinamika cekungan di Pulau Seram termasuk cekungan pada daerah Bula.

Penelitian oleh Setyanta dan Setiadi pada tahun 2010 menggunakan metode gaya berat. Pada penelitian tersebut cekungan ditunjukan oleh kontur anomali 50 mgal hingga 0 mgal berdasarkan petaanomali bouger. Sedangkan batuan penyusun cekungan tersebut diidentifikasi berdasarkan nilai rapat massa dalam pemodelan.

Terdapat beberapa metode geofisika yang digunakan dalam eksplorasi cekungan migas, salah satu metode yang digunakan adalah metode Magnetotelurik (MT). Metode MT mampu memetakan struktur geologi serta menampilkan zona interest berdasarkan kontras tahanan jenis material bawah permukaan.

Dalam penelitian ini, melakukan inversi 1 dan 2 dimensi resistivitas bawahpermukaan berdasarkan data magnteotelurik. Prosedur pada penelitian ini adalah: mengubah data time series menjadi frekuensi, robust processing, robust processing up, combine, seleksi cross power, mengubah data menjadi EDI file, melakukan inversi dan kemudian menginterpretasi data magnetotelurik yang telah diolah.

\section{TINJAUAN PUSTAKA}

\subsection{Lokasi Daerah Penelitian}

Lokasi penelitian ini terletak di wilayah Bula di Kabupaten Maluku Tengah, Secara koordinat berada pada 4 00' LS. Batas utara dan timur ialah Laut
Seram, di selatan Laut Banda dan di barat Lembar Masohi.

\subsection{Struktur Geologi dan Tektonika}

Kawasan Indonesia Timur, termasuk Busur Banda adalah tempat berinteraksinya lempeng-lempeng aktif di dunia, yakni Lempeng Filipina, Lempeng Laut Banda, Lempeng Australia, dan Lempeng Pasifik (de Smet dalam Setyanta dan Setiadi, 2010). Tektonis pada interaksi tersebut melahirkan sesar besar yang berasosiasi dengan vulkanisme dan lipatan.

Salah satu akibat lainnya dari interaksi beberapa lempeng tersebut adalah terbentuknya rangkaian busur luar, busur dalam (busur vulkanik), dan cekungancekungan sedimentasi yang disertai dengan kompleksitas deformasi litologi.

Struktur perdauan (foliasi) dijumpai pada batuan malihan dengan arah yang tidak teratur. Kekar yang kecil dijumpai pada batuan yang tua, tetapi jarang pada batuan yang berumur Tersier Akhir sampai Kuarter. Sesar yang dijumpai adalah sesar naik, sesar turun, dan sesar geser jurus. Sesar naik terjadi pada batuan malihan, sedimen Trias-Jura dan batuan yang berumur Miosen. Ditafsirkan, sesar naik ini terjadi pada kala Miosen Akhir. Arah jurusnya lebih kurang baratlaut-tenggara dengan kemiringan ke arah baratdaya (Gafoer dkk, 1993).

\subsection{Fisiografi Regional}

Morfologi daerah ini dipengaruhi oleh sebaran batuan serta keadaan strukturnya. Setiap satuan morfologi mencerminkan batuan tertentu dengan pola aliran sungainya yang mendaun atau menyiku. Lembar ini dapat dibedakan tiga satuan Morfologi, yakni: pegunungan, perbukitan dan dataran (Gafoer dkk, 1993). 


\subsection{Stratigrafi}

Urut-urutan stratigrafi secara garis besarnya dapat dijelaskan sebagai berikut: Pertama adalah Seri Australia yang terdiri atas kelompok batuan malihan Formasi Kanikeh (Trias), Formasi Saman saman (Trias-Jura), Karbonat Manusela (Jura) dan Kelompok Nief (Kapur-Miosen Akhir). Kedua adalah Seri Seram yang diawali dengan terobosan batuan vulkanik (Ambon Volcanic) dan disusul dengan pengendapan Formasi Wahai (Pleistosen Awal) dan Formasi Fufa (Pleistosen Akhir) (Kemp \& Mogg, 1992).

\section{TEORI DASAR}

\subsection{Metode Magnetotelurik}

Metode Magnetotelurik (MT) merupakan suatu metode eksplorasi geofisika pasif yang bertujuan untuk merekam besarnya medan elektromagnetik bumi alami, guna mengetahui kondisi bawah permukaan. Konsep gelombang elektromagnetik yang mendasari metode magnetotelurik ini adalah konsep Persamaan Maxwell, khususnya dalam Persamaan Hukum Ampere dan Persamaan Hukum Faraday (Simpson dan Bahr, 2005).

\subsection{Konsep Dasar Metode MT}

Persamaan Maxwell merupakan sintesa hasil-hasil eksperimen mengenai fenomena listrik magnet yang didapatkan oleh Faraday, Ampere, Gauss, Coulumb disamping dilakukan oleh Maxwell sendiri (Grandis, 2010). Dalam bentuk diferensial, Persamaan Maxwell dalam domain frekuensi dapat ditulis sebagai berikut:

$$
\begin{aligned}
& \nabla x \boldsymbol{E}=-\frac{\partial B}{\partial t} \\
& \nabla x \boldsymbol{H}=\boldsymbol{j}+\frac{\partial D}{\partial t} \\
& \boldsymbol{\nabla} \cdot \boldsymbol{D}=\boldsymbol{q} \\
& \nabla . \boldsymbol{B}=0
\end{aligned}
$$

Persamaan (1) menunjukkan hukum Faraday, dimana medan listrik dihasilkan dari medan magnet yang berubah terhadap waktu. Persamaan(2) merupakan generalisasi teorema Ampere dengan memperhitungkan hukum kekekalan muatan.

Persamaan tersebut menyatakan bahwa medan magnet timbul akibat fluks total arus listrik yang disebabkan oleh arus konduksi dan arus perpindahan. Persamaan (3) menyatakan hukum Gauss yaitu fluks elektrik pada suatu ruang sebanding dengan muatan total yang ada dalam ruang tersebut.

Sedangkan persamaan (4) yang identik dengan persamaan (3) berlaku untuk medan magnet, namun dalam hal ini tidak ada monopol magnetik.

\subsection{Impedansi Bumi Homogen}

Model bumi yang paling sederhana adalah suatu half-space homogen isotropik dimana diskontinyuitas tahanan-jenis hanya terdapat pada batas udara dengan bumi. Dalam hal ini setiap komponen horisontal medan listrik dan medan magnet hanya bervariasi terhadap kedalaman.

\subsection{Impedansi Bumi Berlapis Horizontal}

Impedansi dinyatakan $\stackrel{\circ b}{\rightarrow}$ agai perbandingan antara medan $\operatorname{listrik}(\overrightarrow{\boldsymbol{E}})$ dan medan magnet $(\overrightarrow{\boldsymbol{H}})$ bergantung pada tahanan-jenis medium atau batuan. Dengan demikian, impedansi sebagai fungsi dari perioda memberikan informasi mengenai tahanan-jenis medium sebagai fungsi dari kedalaman. Berdasarkan hal tersebut metoda sounding MT dilakukan dengan merekam data berupa variasi medan listrik dan medan magnet pada beberapa perioda tertentu. 


\subsection{Skin Depth}

Besaran skin depth digunakan untuk memperkirakan kedalaman penetrasi atau kedalaman investigasi gelombang elektromagnetik. Adapun skin depth dalam metodeMagnetotelurik memenuhi

Persamaan berikut ini:

$$
\delta=503 \sqrt{\frac{\rho}{f}}(\mathbf{k m})
$$

Persamaan (5), terlihat bahwa skin depth dipengaruhi oleh besarnya frekuensi alat yang kita gunakan dan resistivitas Formasi. Semakin besar frekuensi alat yang kita gunakan, maka penetrasi yang diperoleh akan semakin dangkal. Namun, ketika frekuensi alat yang digunakan semakin kecil, maka penetrasi yang dihasilkan akan semakin dalam.

\subsection{Transformasi Fourier}

Secara prinsip, transformasi fourier merupakan suatu operasi matematis yang mengubah sinyal menjadi spectrum. Berikut ini adalah fungsi dari fourier transform dengan $x(\omega)$ adalah fungsi gelombang dalam domain frekuensi $x(t)$ adalah fungsi gelombang dalam domain waktu, $i$ adalah bilangan imaginer, $\omega=2 \pi f$ adalah frekuensi angular dan $t$ adalah waktu.

\subsection{Transverse Magnetic Mode (TM) dan Transverse Electric Mode (TE)}

Pada kasus 2 dimensi terdapat dua jenis modus yaitu modus TE dan TM. Modus TE merupakan modus yang mengukur medan listrik searah dengan strike dan medan magnet tegak lurus dengan strike. Sedangkan modus TM merupakan modus yang mengukur medan magnet searah dengan strike dan medan listrik tegak lurus dengan strike.

\subsection{Inversi Non Linier \\ Conjugate Gradient (NLCG)}

Inversi adalah suatu proses pengolahan data lapangan yang melibatkan teknik penyelesaian matematika dan statistik untuk memperoleh distribusi sifat fisis bawah permukaan. Analisis terhadap data lapangan dilakukan dengan cara melakukan pencocokan kurva antara model matematika dengan data lapangan.

Pada penelitian ini digunakan metode inversi Nonlinear Conjugate Gradient (NLCG). Metode NLCG merupakan jenis inversi dapat digunakan untuk meminimalisasi objective functional (S). Fungsi objek berisi jumlah beban weigthed dari model fungsi objektif dan data misfit.

$$
S=\emptyset_{d}+\tau \emptyset_{m}
$$

merupakan data mistit dan merupakan model fungsi objektif. adalah parameter regulasi yang mengontrol trade off dan . dipilih agar sama dengan nilai konsistensi error data. Nilai semakin besar mengindikasikan model cocok dengan data. Inversi 2D untuk mengatur model fungsi objektif dan data misfit sama dengan

$$
\begin{aligned}
& \emptyset_{m}=\| L\left(m-m_{0} \|^{2}\right. \\
& \emptyset_{d}=(d-F(m))^{2} R_{d d}^{-1}(d-F(m))
\end{aligned}
$$

\section{Keterangan :}

$L=$ operator linier

$m$ = model vektor unkown

$=$ model awal

$d \quad=$ vektor data observasi

$F(m)=$ operator pemodelan forward

$R_{d d}=$ matrik kovarian error

Operator linier yang dipilih adalah

Laplacian $L=\Delta$

$$
\| L\left(m-m_{0} \|^{2}=\int \Delta\left(\left(m_{(x, z)}-m_{0(x, z)}\right)\right)^{2} d x d z(10)\right.
$$

Solusi masalah inversi dilakukan dengan iteratif, metode NLCG mengaplikasikan secara langsung 
minimalisasi dari S. Rangkaian model diberikan oleh:

$$
m^{i+1}=m^{i}+a^{i+1} h^{i-1}
$$

adalah arah pencarian didapatkan dari NLCG dan dihitung untuk meminimumkan $\mathrm{S}$ dengan line search. Misfit rata-rata antara data prediksi dan data observasi diwakili oleh eror RMS (root mean square). Eror RMS untuk program inversi 2D ditentukan dengan

$$
R M S=\sqrt{\frac{(d-F(m))^{T} R_{d \frac{d}{d}}^{-1}(d-F(m))}{N}}
$$

$\mathrm{N}$ adalah jumlah titik data.

Proses update model dengan mencari nilai yang meminimalisasi fungsi . $\mathrm{W}\left(m_{k}+\alpha_{k} u_{k}\right)$. logaritma ini membutuhkan hasil dari $J$ atau $J^{T}$. Efisiensi komputasi algoritma ini, dikontrol oleh jumlah iterasi $\left(\mathrm{N}_{\mathrm{cg}}\right) . \mathrm{N}_{\mathrm{cg}}$ adalah fungsi dari $\lambda$. Nilai $\lambda$ yang besar akan membutuhkan $\mathrm{N}_{\mathrm{cg}}$ yang kecil. Akan tetapi, nilai $\lambda$ yang kecil akan membutuhkan $\mathrm{N}_{\mathrm{cg}}$ yang besar (Siripunvarapon dkk, 2007).

Pendekatan Hessian yang berkorelasi dengan Laplacian operator untuk meningkatkan efisiensi pre-conditioner. Dengan pre-conditioner, jumlah iterasi yang dibutuhkan untuk mencapai konvergensi ke level yang diinginkan menjadi sangat berkurang hal ini menunjukkan bahwa jumlah konvergensi dapat dicapai dengan iterasi yang sedikit.

\section{METODE PENELITIAN}

\subsection{Alat dan Bahan Penelitian}

a. Data Magnetotelurik;

Data magnetotelurik yang digunakan adalah data sekunder di daerah hidrokarbon, Bula, Maluku Tengah.

b. Software dan hardware

Software yang digunakan dalam penelitian ini adalah Software RockWorks15, Microsoft Excel, Software (53), Surfer10, Software
Global Mapper12, Software ArcGIS v.10, SSMT2000, MT Editor, dan WinGlink. Hardware yang digunakan yaitu, laptop Acer Aspire 4736Z.

\subsection{Pengolahan Data}

\subsubsection{Pengubahan Time series ke dalam domain frekuensi}

Hasil perekaman pada alat MT yaitu komponen medan listrik dan medan magnet berupa data dalam format time series. Data time series ini akan diubah ke dalam domain frekuensi dengan menggunakan software SSMT 2000 yang didasari oleh konsep Transformasi Fourier.

\subsubsection{Robust Processing}

Robust processing merupakan filter noise. Data diproses dengan menggunakan software SSMT 2000. Robust processing memiliki tiga tipe yaitu no weight, rho variance, ordinary coherency.

\subsubsection{Combine}

Combine merupakan proses penambahan sensor medan magnetik yang memiliki nilai regional yang dapat menjadi acuan medan magnetik lokal. Combine memiliki peranan yang sama seperti remote reference, perbedaan keduanya adalah jarak stasiun yang akan dikoreksi dengan stasiun yang menjadi pengkoreksi.

\subsubsection{Seleksi cross power}

Seleksi cross power dengan menggunakan software MTEditor. Data ditampilkan dalam bentuk kurva apparent resistivity terhadap frekuensi. Kemudian dilakukan pemilihan data. 


\subsubsection{Inversi}

Inversi yang dilakukan yaitu inversi 1D dan 2D dengan menggunakan software WinGlink. Inversi 1D akan menghasilkan profil tahanan jenis setiap titik pengukuran, sedangkan inversi 2D proses pemodelan distribusi tahanan jenis bawah permukaan.

\section{HASIL DAN PEMBAHASAN}

\subsection{Titik Pengukuran MT}

Jumlah titik pengukuran MT adalah 7 titik dengan arah lintasan timurlaut baratdaya. Spasi antar titik pengukuran rata-rata 2.5 kilometer. Waktu pengukuran setiap titik yaitu selama 12 jam.

\subsection{Hasil Koherensi Data}

Pengolahan data dengan melakukan robust processing bertujuan untuk mereduksi noise dengan meningkatkan nilai koherensi seperti yang telah dijelaskan pada bab metode penelitian. Hasil nilai koherensi data yang diolah dapat dilihat pada Tabel 1. Nilai koherensi pada titik MT2 setelah di upgrade kurang dari $75 \%$ bahkan bernilai lebih kecil dari tipe robust sebelum di upgrade.

Data dengan nilai koherensi di bawah 75\% berarti kualitas data ini kurang baik sehingga perlu dilakukan pemrosesan data selanjutnya yaitu combine. Sedangkan pada titik yang lain dianggap telah tereduksi noise karena memiliki nilai koherensi diatas $75 \%$.

Dapat dilihat pada Tabel 2. nilai koherensi setelah dilakukan combine meningkat, berarti tingkat kualitas data semakin baik.

\subsection{Hasil Inversi 1D Data MT}

Inversi 1D menunjukkan nilai resistivitas terhadap kedalaman. Pada inversi 1D digunakan mode invariant.
Kurva inversi 1D terdapat 2 kurva yang berbeda warna. Hijau merupakan bostick dan merah muda merupakan occam. Kurva bostick merupakan apparent resistivity sedangkan occam merupakan true resistivity seperti pada Gambar 1.

Dapat dilihat pada Tabel 3. kedalaman 48.16 meter hingga 1763.82 meter memiliki nilai resisitivitas yang rendah yaitu antara $4-15 \Omega \mathrm{m}$ diduga sebagai batulempung pada Kompleks Salas.

Kedalaman 1763.82 meter hingga 2770.27 meter memiliki nilai resistivitas yang $23.54 \Omega \mathrm{m}$ diduga batupasir pada Formasi Kanikeh dan pada kedalaman 2770.27 meter hingga 5500 meter dengan nilai resisitivitas $6.98 \Omega \mathrm{m}$ diduga batulempung pada Formasi Kanikeh.

Tabel resistivitas Telford (1990) menjadi acuan dalam mengidentifikasi litologi hasil inversi 1D yang ditunjukkan pada Tabel 4.

\subsection{Hasil Inversi 2D Data MT}

Inversi 2D merupakan penampang distribusi resisitivitas batuan bawah permukaan dengan menggabungan titiktitik pengukuran Magnetotelurik. Proses inversi 2D dengan software WinGlink dan didapatkan distribusi resistivitas seperti pada Gambar 3.

Berdasarkan informasi geologi pada Gambar 2. dan hasil inversi 2D pada Gambar 3. dapat diindentifikasikan bawah permukaan berdasarkan nilai resistivitas telford pada Tabel 4. sebagai acuan.

Berdasarkan sayatan geologi pada Gambar 2. Formasi pada daerah penelitian ini dari arah Timurlaut-Baratdaya yaitu Formasi Wahai, Formasi Kanikeh dan Kompleks Salas.

Pada nilai resistivitas rendah yaitu sekitar $7-16 \Omega \mathrm{m}$ disepanjang titik MT1 hingga MT7 pada kedalaman mencapai 1000 meter diidentifikasikan sebagai batu lempung.

Batu lempung merupakan batuan yang bersifat impermeable yang menahan fluida 
pada batuan serta sulit untuk meloloskannya, sehingga batu lempung ini dapat diidentifikasikan sebagai cap rock atau batuan penutup.

Penampang resistivitas dengan nilai 34-120 $\Omega \mathrm{m}$ diantara titik MT6 dan MT7 pada kedalaman sekitar 1500 meter merupakan batu pasir. Batu pasir yang bersifat permeable yaitu dapat meloloskan dan menyerap fluida serta memiliki permeabilitas dan porositas yang baik. Sehingga, batupasir dapat diidentifikasikan sebagai batuan reservoir. Menurut Zillman dan Paten (1975) batuan reservoir pada cekungan di daerah Bula yaitu batu pasir.

Penampang resistivitas hasil inversi 2D pada Gambar 3. menunjukan adanya sesar berdasarkan nilai resistivitas yang kontras dan informasi geologi oleh Gafoer dkk (1993) pada Gambar 2, yaitu antara titik pengukuran MT2 dan MT3, MT3 dan MT4 serta MT6 dan MT7.

\section{KESIMPULAN DAN SARAN}

\subsection{Kesimpulan}

Adapun kesimpulan yang dapat diambil pada penelitian yang telah dilakukan adalah:

1. Berdasarkan data geologi dapat diidentifikasikan Formasi pada daerah penelitian yaitu Formasi Wahai yang terdiri dari batu napal yang bersisipan dengan batu gamping pasiran dan batupasir halus, Formasi Kanikeh yang terdiri dari batupasir, batulanau dan batulempung serta Kompleks Salas yang terdiri dari batu beku, sedimen dan metamorf yang menyatu pada massadasar lempungan.

2. Data magnetotelurik penelitian ini memiliki kualitas yang baik.

3. Hasil pengolahan data dan inversi $2 \mathrm{D}$ data magnetotelurik didapatkan:

a. Lapisan dengan nilai resistivitas 7 - $16 \Omega \mathrm{m}$ disepanjang titik MT1 hingga MT7 pada kedalaman mencapai 1000 meter diduga batu lempung yang diindikasikan sebagai cap rock.

b. Lapisan dengan nilai resistivitas $34-120 \Omega \mathrm{m}$ pada titik MT6 dan MT7 pada kedalaman sekitar 1500 meter diduga batu pasir yang diindikasikan sebagai reservoir.

4. Hasil inversi 2D data magnetotelurik memiliki kesamaan dengan model geologi daerah penelitian.

\subsection{Saran}

Adapun saran yang dapat diberikan adalah:

1. Sebaiknya didukung oleh data log pada titik pengukuran MT agar semakin jelas litologi bawah permukaan daerah penelitian.

2. Sebaiknya penelitian tidak hanya 1 line saja agar penampang 2D dapat lebih mudah diinterpretasikan.

\section{UCAPAN TERIMA KASIH}

Penulis mengucapkan terima kasih kepada Noor Muhammad Indra Giri dan Hidayat (Pusat Survei Geologi, Bandung) sebagai pembimbing lapangan, serta Syamsurijal Rasimeng S.Si., M.Si dan Karyanto, S.Si., M.T. yang telah membimbing dan memberikan dukungan terhadap penyelesaian penelitian ini.

\section{DAFTAR PUSTAKA}

Amriyah, Q., 2012, Pemodelan Data Magnetotelurik Multidimensi untuk Mendeliniasi Sistem Geotermal Daerah Tawau Malaysia, Skripsi, Depok: Universitas Indonesia.

Audley-Charles, M.G., Carter D.J. dan Barber A.J., 1975, Stratigrapic Basin for Tectonic Interpretations of the Banda Arcs, Eastern 
Indonesia, Proc. Indones

Petroleum Association $3^{\text {rd }}$ Annual Convention, p. 25-44.

Badan Informasi Geospasial. 2015.

Peta Rupa Bumi Provinsi Maluku skala 1:250.000. Jakarta :

Permendagri.

Daud, Y., 2010, Metode Mangnetotelurik Laboratorium Geofisika, Depok: FMIPA UI.

Erdiansyah, E., Iryanti, M. dan Wardana, D.D., 2015, Identifikasi Struktur

Bawah Permukaan dengan

Menggunakan

Metode

Magnetotelurik Daerah Sekitar Bogor Jawa Barat Sebagai Potensi Sistem Hidrokarbon, Fisika, Vol. 3, No.1, p.1-9.

Gafoer S., Suwitodirdjo K. dan Suharono, 1993, Peta Geologi Lembar BulaWatubela, Maluku Skala 1:250.000, Bandung: Pusat Survei Geologi.

Grandis, H., 2010, Metode Magnetotelurik (MT),http://hendragrandis.file.word p ress.com /2010/01/mt_teks1.pdf.

Green, A.M., 2003, Magnetotelluric Crustal Studies in Kenai, Alaska, Colorado: School of mines.

Kusworo dan Aries, 2014, Tabel Nilai Porositas, Bandung:Pusat Survei Geologi

Rodi, W. dan Mackie, R.L., 2001, Nonlinier Conjugate Gradient Alogarithm for 2D Magnetotelluric Inversion, Geophysics Vol. 66, No.1, p. 174-187.

Setyanta, B. dan Setiadi, E., 2010, Pola

Struktur dan Geodinamika

Cekungan Bula Berdasarkan Anomali Gaya Berat, Geophysics Vol. 20, No.1, p. 41-55.
Siripunvarapon, W., Egbert, G., Lenbury, Y., dan Uyeshima, M., 2005, Three- dimensional Magnetotelluric Inversion: Data Space Method, Physics of The Earth and Planetary Interiors, Vol 150, p. 3-14.

Simpson dan Bahr., 2005 Pratical Magnetotellurics, Cambridge:

Cambride University Press.

Supriyanto., $\quad$ 2007, Analisis Data

Geofisika:Memahami Teori Inversi, Depok: Universitas Indonesia.

Telford, W., Geldart M.L.P. dan Sheriff R.E., 1990, Applied Geophysics

Second Edition, Cambridge: Cambridge University Press.

Unsworth, 2006, Overview of Elektromagnetic Exploration Methods, Geophysics 424, Kanada: University of Alberta.

Vozoff, K., 1972, The Magnetotelluric Method in the Exploration of Sedimentary Basins, Geophysics, Vol 37, p. 98 - 141.

Wachisbu, MIM. dan Santosa, B.J., 2015, Pemodelan Data Magnetotelurik dengan Remote Reference untuk Eksplorasi Cekungan Migas Studi Kasus: Lapangan Em-4, Fisika Vol. 4, No.1, p. 17-20.

Zillman, N.J. dan Paten R.J., 1975, Geology and petroleum prospects of Seram Island, Eastern Indonesia, A.P.E.A.J., Vol. 15, No. 1, p.73-80. 


\section{LAMPIRAN}

Tabel 1. Hasil nilai koherensi data

\begin{tabular}{|l|l|l|l|l|}
\hline \multirow{2}{*}{ Stasiun } & \multicolumn{4}{|c|}{ Koherensi } \\
\cline { 2 - 5 } & \multicolumn{1}{|c|}{ NW } & RV & OC & UP \\
\hline MT1 & 83.890134 & 84.9735 & 85.1599 & 85.8252 \\
\hline MT2 & 69.963148 & 73.2942 & 74.2235 & 72.1593 \\
\hline MT3 & 84.2632561 & 84.9053 & 85.6265 & 86.8237 \\
\hline MT4 & 81.1180012 & 81.6626 & 82.5317 & 83.8954 \\
\hline MT5 & 78.9476904 & 78.8278 & 79.177 & 80.5498 \\
\hline MT6 & 74.3366406 & 74.7625 & 76.1429 & 77.0086 \\
\hline MT7 & 78.13572 & 78.6152 & 80.0422 & 82.7725 \\
\hline
\end{tabular}

Tabel 2. Sebelum combine (a) sesudah combine (b)

\begin{tabular}{|l|l|l|l|l|}
\hline \multirow{2}{*}{ STASIUN } & \multicolumn{4}{|c|}{ RHOBUST TERBAIK } \\
\cline { 2 - 5 } & \multicolumn{1}{|c|}{ RHOBUST } & CXY & CYX & AVERAGE \\
\hline MT1 & OC UP AUTO & 85.75323 & 85.89709 & 85.82516 \\
\hline MT2 & OC AUTO & 74.79076 & 73.47389 & 74.13233 \\
\hline MT3 & OC UP AUTO & 87.45761 & 86.18985 & 86.82373 \\
\hline MT4 & OC UP AUTO & 87.4857 & 80.30517 & 83.89544 \\
\hline MT5 & OC UP AUTO & 83.99704 & 77.1025 & 80.54977 \\
\hline MT6 & OC UP AUTO & 78.12629 & 75.89095 & 77.00862 \\
\hline MT7 & OC UP AUTO & 82.59734 & 82.94775 & 82.77255 \\
\hline
\end{tabular}

(a) 


\begin{tabular}{|l|l|l|l|l|}
\hline \multirow{2}{*}{ STASIUN } & \multicolumn{4}{|c|}{ RHOBUST TERBAIK } \\
\cline { 2 - 5 } & RHOBUST & CXY & CYX & AVERAGE \\
\hline MT1 & OC UP AUTO & 85.7532 & 85.8971 & 85.8251599 \\
\hline MT2 & OC AUTO & 81.5456 & 80.2944 & 80.9200203 \\
\hline MT3 & OC UP AUTO & 87.4576 & 86.1898 & 86.8237275 \\
\hline MT4 & OC UP AUTO & 87.4857 & 80.3052 & 83.8954366 \\
\hline MT5 & OC UP AUTO & 83.997 & 77.1025 & 80.5497724 \\
\hline MT6 & OC UP AUTO & 78.1263 & 75.891 & 77.0086202 \\
\hline MT7 & OC UP AUTO & 82.5973 & 82.9477 & 82.7725462 \\
\hline
\end{tabular}

(b)

Tabel 3. Resistivitas dan ketebalan lapisan pada titik MT1

\begin{tabular}{|l|l|l|l|}
\hline $\begin{array}{c}\text { Depth to } \\
\text { Top }(\boldsymbol{m})\end{array}$ & \multicolumn{1}{|c|}{$\begin{array}{c}\text { Depth to } \\
\text { base }(\boldsymbol{m})\end{array}$} & $\begin{array}{c}\text { True } \\
\text { resistivity } \\
(\mathbf{\Omega m})\end{array}$ & \multicolumn{1}{|c|}{ Lithology } \\
\hline 0 & 48.16 & 9.73 & Claystone \\
\hline 48.16 & 87.76 & 4.14 & Claystone \\
\hline 87.76 & 151.89 & 15.17 & Claystone \\
\hline 151.89 & 250.16 & 4.46 & Claystone \\
\hline 250.16 & 675.34 & 7.11 & Claystone \\
\hline 675.34 & 1763.82 & 8.93 & Claystone \\
\hline 1763.82 & 2770.27 & 23.54 & Sandstone \\
\hline 2770.27 & 5500 & 6.98 & Claystone \\
\hline
\end{tabular}


Tabel 4. Nilai resistivitas batuan (Telford, 1990).

\begin{tabular}{|c|c|}
\hline Rock type & Resistivity range $(\Omega \mathrm{m})$ \\
\hline Sandstone & $1-7.4 \times 10^{8}$ \\
\hline Limestone & $5 \times 10-10^{\prime}$ \\
\hline Marls & $3-7 \times 10$ \\
\hline Claystone & $1-10^{2}$ \\
\hline Shale & $20-2 \times 10^{5}$ \\
\hline Conglomerates & $2 \times 10^{5}-10^{4}$ \\
\hline Chalk & $50-150$ \\
\hline Gabro & $10^{5}-10^{6}$ \\
\hline
\end{tabular}

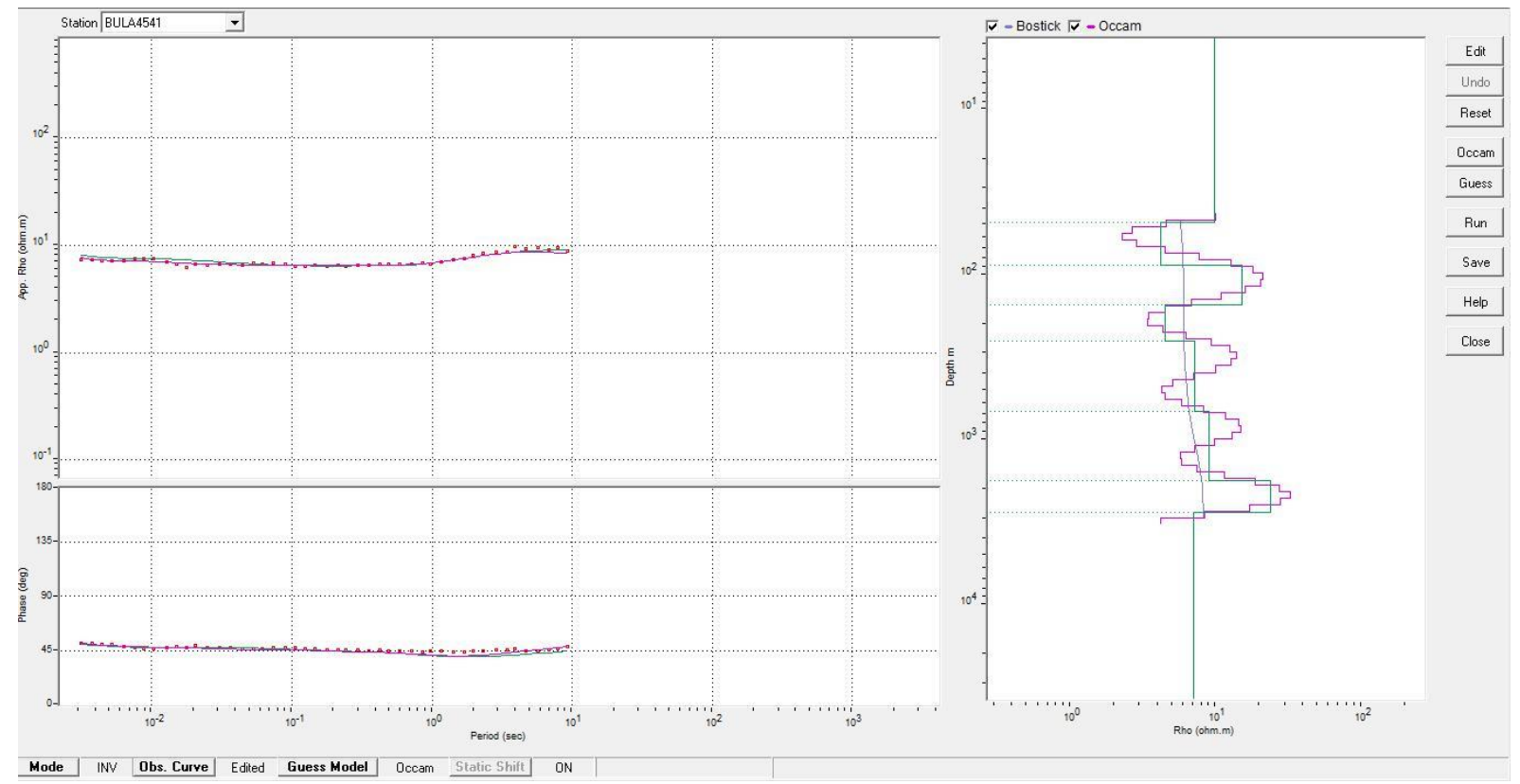

Gambar 1. Inversi 1D data MT 


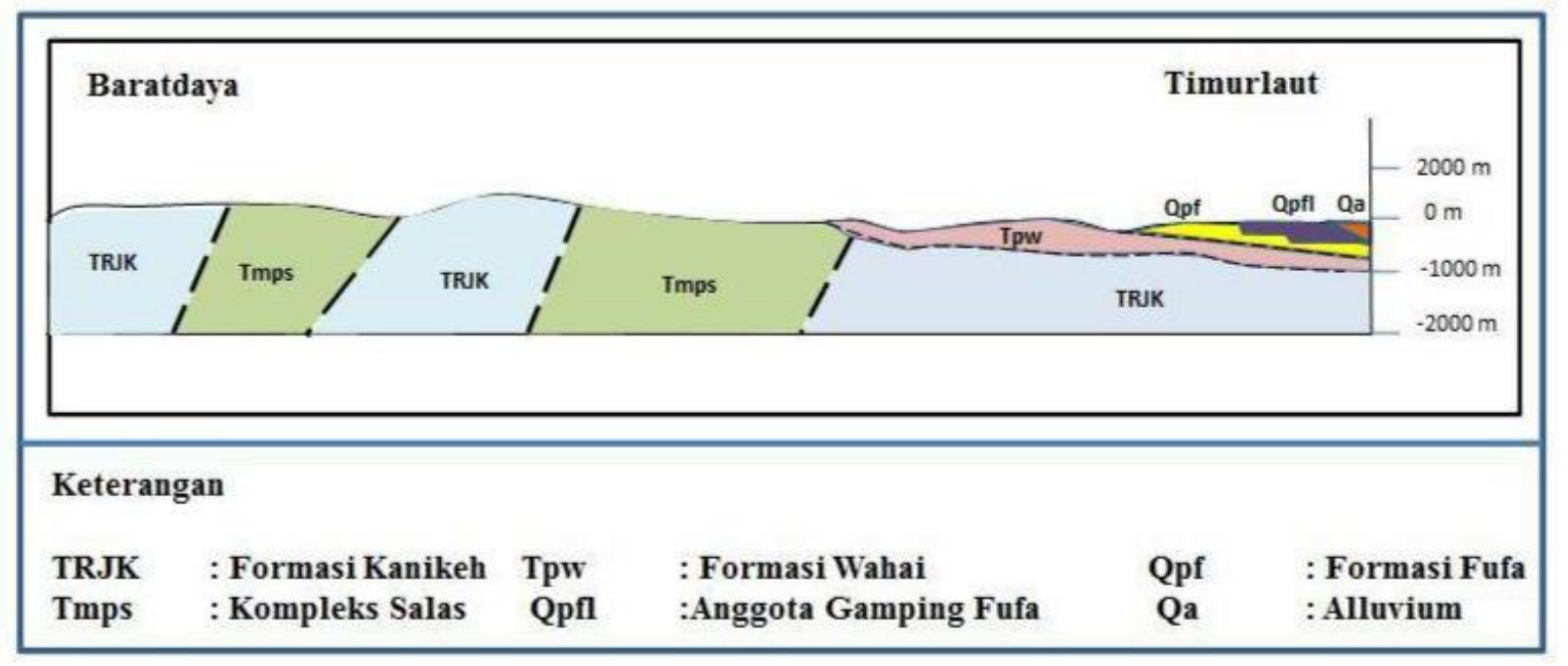

Gambar 2. Sayatan geologi daerah penelitian

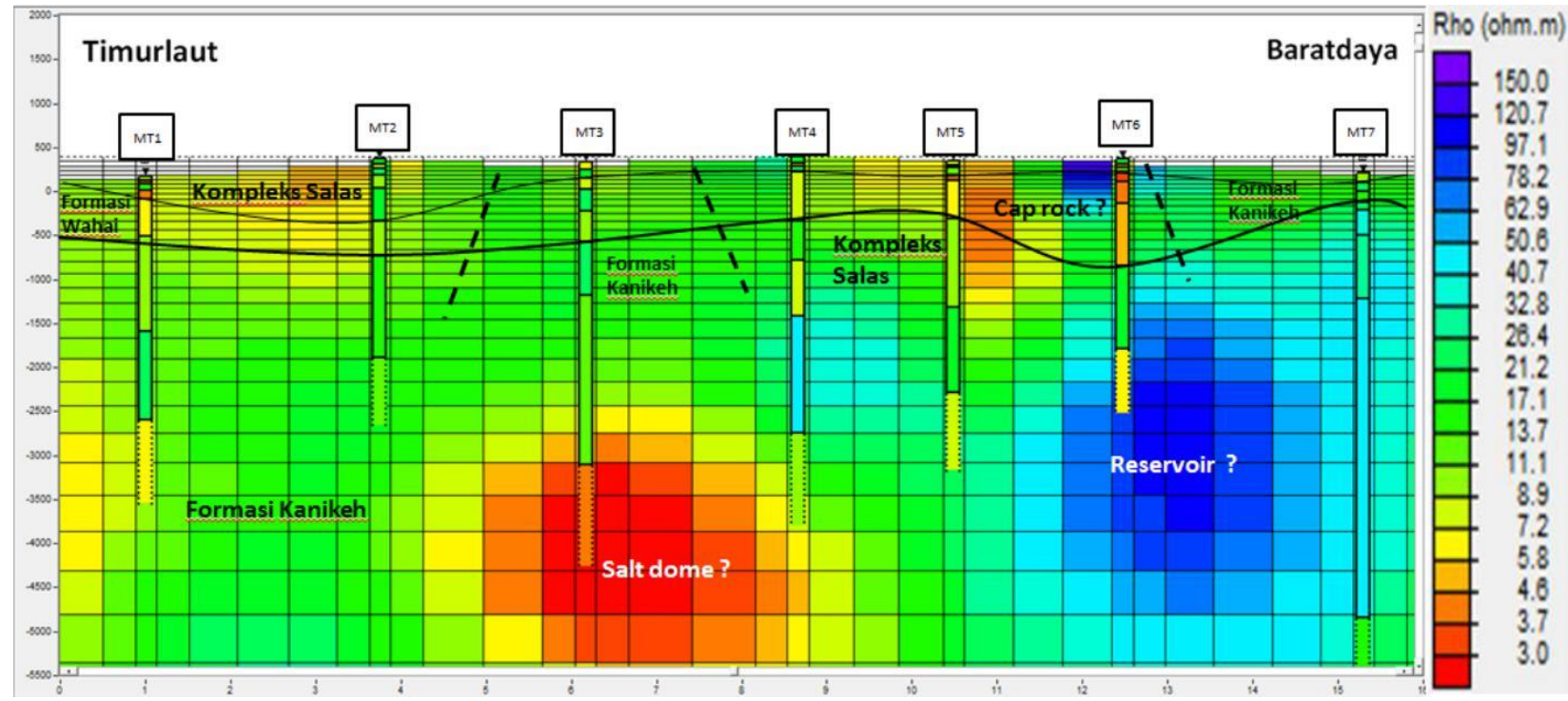

Gambar 3. Inversi 2D data MT 